\title{
Patates Glykoalkaloidleri: Özellikleri ve Biyolojik Aktiviteleri
}

\section{Potato Glykoalkaloids: Properties and Biological Activities}

Fatma Zehra OKD
Arif ŞANLIID

Isparta Uygulamalı Bilimler Üniversitesi Ziraat Fakültesi Tarla Bitkileri Bölümü, Isparta, Türkiye

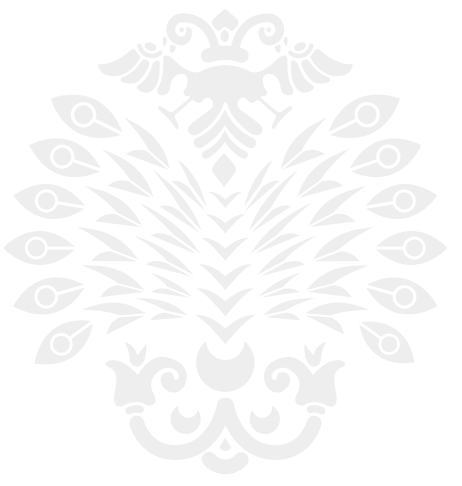

Geliş Tarihi/Received: 16.07.2021 Kabul Tarihi/Accepted: 04.01.2022

Sorumlu Yazar/Corresponding Author: Arif ŞANLI

E-mail: arifsanli@isparta.edu.tr

Cite this article as: Ok, F. Z., \& Şanlı, A. (2022). Potato Glykoalkaloids: Properties and Biological Activities. Atatürk University Journal of Agricultural Faculty, 53(1), 88-96

\section{öz}

Ekonomik olarak üretimi yapılan bitkilerden patates başta olmak üzere, Solanaceae familyası üyelerinin önemli bir kısmında solanin, çakonin, solasonin ve tomatin gibi bazı glikoalkaloidler bulunmaktadır. Patateste glikoalkaloid içeriği çevre koşulları ile birlikte genetik olarak da kontrol edildiği için çeşide bağı olarak önemli derecede değişim göstermektedir. Büyüme koşulları, depolama, taşıma, mekanik zarar, sürgün gelişimi, fitopatojenler, ısı ve ışığa maruz kalma gibi faktörler patateste glikoalkaloid birikimini etkileyen diğer önemli faktörlerdir. Patates steroidal glikoalkaloidleri (SGA'lar) zararlılara ve patojenlere karşı bitki direncinin önemli bileşenleri olmakla birlikte, yüksek seviyeleri insanlar için toksik etki gösterebilmektedir. SGA'ların toksisiteleri merkezi sinir sistemini etkileyen antikolinesteraz aktivitesinden ve sindirim sistemi ve diğer organları etkileyen hücre zarı bütünlüğünü bozucu etkilerinden kaynaklanmaktadır. SGA toksisitesinin alt sınırı yenilebilir yumrularda 20 mg/100 g taze ağırlık ile sınırlandııımıştır. Patates gibi insanlar tarafından tüketilen ürünlerde bulunan glikoalkaloidlerin biyolojik etkileri faydalı veya zararlı olabilmektedir. Bu nedenle, yumrudaki toksik glikoalkaloid seviyesinin insanlar açısından zararsız seviyede tutulup, aynı zamanda toprak üstü aksamında yüksek glikoalkaloid seviyesini koruyarak patojen ve zararlı saldırılarına karşı bitki direncinin arttırımasına yönelik çalışmalar yapılmaktadır. Bitkilerin doğaları gereği üretmiş oldukları sekonder metabolitlerin işlev ve fonksiyonlarının bilinmesi ve bu maddelerin hem bitki savunma mekanizması hem de insan sağlığı açısından dokuya özel sentez mekanizmalarının araştırıması, yeni çeşitlerin geliştirilmesinde belirleyici faktörlerden birisi olarak görülmektedir. Bu derlemede, patates glikoalkaloidleri, özellikleri ve biyolojik aktivitelerinin yanı sıra glikoalkaloid birikimini etkileyen faktörler ve toksisiteleri hakkında güncel bilgiler sunulmuştur.

Anahtar Kelimeler: Biyolojik aktivite, patates, glikoalkaloid, solanin, Solanum tuberosum L.

\section{ABSTRACT}

There are some glycoalkaloids such as solanine, chaconine, solasonine, and tomatine in a significant part of the members of the Solanaceae family, especially potatoes, which are economically produced plants. Since the glycoalkaloid content of potatoes is genetically controlled in addition to environmental conditions, it varies considerably depending on the variety. Factors such as growing conditions, storage, transportation, mechanical damage, sprout development, phytopathogens, heat, and light exposure are other important factors affecting glycoalkaloid accumulation in potatoes. Potato steroidal glycoalkaloids are important components of plant resistance to pests and pathogens, but their high levels can be toxic to humans. The toxicities of steroidal glycoalkaloids are due to their anticholinesterase activity affecting the central nervous system and cell membrane disrupting effects affecting the digestive system and other organs. Accordingly, current safety regulations limit their content in the edible tuber to $20 \mathrm{mg}$ per $100 \mathrm{~g}$ fresh weight. The biological effects of glycoalkaloids found in products consumed by humans, such as potatoes, can be beneficial or harmful. Therefore, studies have accelerated to keep the toxic glycoalkaloid level in the tuber at a harmless level for humans and at the same time maintaining a high glycoalkaloid level in the above-ground parts for increasing plant resistance against pathogen and pest attacks. Knowing the functions of the secondary metabolites produced by plants by their nature and investigating the tissue-specific synthesis mechanisms of these substances in terms of both plant defense mechanism and human health are seen as one of the determining factors in the development of new varieties. Therefore, this review focuses on potato glycoalkaloids, their properties, and biological activities as well as the factors affecting glycoalkaloid accumulation and their toxicities.

Keywords: Biological activity, potato, Glycoalkaloid, solanine, Solanum tuberosum L. 


\section{Giriş}

Steroidal Glikoalkaloidler (SGA) ekonomik öneme sahip patates ve domates gibi Solanaceae familyası üyeleri başta olmak üzere çok çeşitli bitki türünde sentezlenen sekonder metabolitlerdendir. Çeşitli patates türlerinde 80'den fazla farklı SGA tanımlanmıştır. Bununla birlikte, aglikon solanidinden türetilen $\alpha$-çakonin $(\alpha$-chaconine) ve $\alpha$-solanin ( $\alpha$-solanine), kültürü yapılan patateslerin (Solanum tuberosum L.) iki ana SGA'sını oluşturmakta olup, $\alpha$-solanin/ $\alpha$-çakonin oranı dokular, genotipler ve yetişme koşullarına bağlı olarak büyük farklılıklar göstermektedir (Friedman \& Dao, 1992; Sarquís ve ark., 2000). Patateste SGA seviyesi bitkinin genetik kapasitesine ve çevre faktörlerine bağlı olarak değişim göstermektedir (Friedman, 2006). Bununla birlikte çevresel stres faktörleri de SGA birikimini tetiklemektedir (Papathanasiou ve ark., 1999; Sharma \& Salunkhe, 1989). Hasat, taşıma ve depolama sırasında oluşan yumru hasarı, patojenlere maruz kalma, güneş veya direkt ışık alma ve ısıya maruz kalma süreci SGA seviyesinin artmasına neden olmaktadır (Friedman, 2006; Kirui ve ark., 2009). Patateste SGA'lar tüm bitki organlarına yayılmış durumda olup, olgunlaşmamış meyvelerde, genç yapraklarda, çiçeklerde ve sürgünlerde (metabolik aktif kısımlar) yüksek konsantrasyonda bulunmaktadır (Smith ve ark., 1996) Genel olarak taze yumruların SGA içerikleri çeşide bağlı olarak 22,4-208,9 mg/kg arasında değişmektedir (Friedman \& McDonald, 1999).

Bitkiler tarafından böceklere ve patojenlere karşı doğal savunma mekanizması olarak üretilen SGA'lar belirli konsantrasyonlarda ağız yolu ile alınması durumunda insanlar için de zararlı etkilere sahip olabilmektedirler. SGA'ların toksik doğaları gereği özellikle yüksek miktarlarda kullanıldığında insanlar üzerine gösterdikleri olumsuz etkileri, bu metabolitlerin kültür bitkilerinde sentezlenme miktarlarının azaltılmasını zorunlu hale getirmiştir (Friedman, 2004, 2006; Kirui ve ark., 2009). Bununla birlikte, gıda güvenliği amacıyla bitki SGA'larının azaltılması ya da sentezlerinin engellenmesi, patojenlere karşı bitki direncinin azalmasına neden olmaktadır. Bitki gelişimi sırasında farklı organlarda SGA birikimi farklı seviyelerde olması (Deahl ve ark., 1991; Eltayeb ve ark., 1997; Friedman \& Dao, 1992; Valkonen ve ark., 1996), genetik mühendisliği çalışmaları ile SGA sentezleyen bitkilerde yapraklar gibi gıda olarak tüketilmeyen organlarda doğal savunma mekanizmasının güçlendirilmesi için SGA miktarının arttırılmasına ya da tüketime yönelik olarak üretilen yumrulardaki SGA seviyesini insan sağlığıyla ilgili kaygıları gidermek için sınırlandırmaya fırsat sunmaktadır.

Gıda sektörünün temel hammadde kaynaklarından birisi olan ve her geçen gün tüketimi artan patates bitkisinde böcek ve patojenlere karşı savunma mekanizması oluşturmak için farklı organlarda değişik konsantrasyonlarda SGA sentezlenmektedir. Patates SGA'ları böcek ve patojenlere karşı savunma mekanizması oluştururken, insanlar için toksik etki gösterebilmektedir. Bu nedenle, bu derlemede patates glikoalkaloidleri, biyosentezi, bitkideki dağılımları, birikimini etkileyen faktörler, biyolojik aktiviteleri ve toksisiteleri konularında bilgiler verilmiş ve SGA'ların hem bitki savunma mekanizması hem de insan sağlığı açısından önemine değinilmiştir.

\section{Glikoalkaloidlerin Kimyasal Yapısı ve Biyosentezi}

Solanaceae alkaloidleri steroidal ve trophan alkaloidleri olmak üzere iki ana gruba ayrılmaktadır. Patates bitkisi steroidal glikoalkaloidlere (SGA) ilave olarak kalistegin alkaloidleri, proteaz inhibitörleri, lektinler ve fenolik bileşikler gibi diğer biyolojik aktif sekonder bileşikleri de sentezlemektedir (Friedman et al., 1997). SGA'lar triterpen türevi metabolitler ve steroidlerle benzer bir öncü olan kolestrolden sentezlenmektedir. SGA'ların biyosentezi, ilk bölümünü C5 birimlerinin oluşumunu ve yoğunlaşmasını içeren üç bölüme ayrılabilir. Sitozolde lokalize olan mevalonat döngüsü aracılığıyla C5 izoprenoid ünitelerinin üretiminde Asetil-CoA kullanılır. Üçlü izoprenoid üniteleri baştan sona 2-trans,6-transfarnesil difosfat (FPP) den yoğunlaşmaktadır.

FPP, iki FPP molekülünü 2,3-oksidoskualen yoğunlaştıran ve triterpen (sterol) biyosentezine öncülük eden skualen sentaz enzimi ile fitoaleksinler (rishitin ve lubimin gibi) dahil olmak üzere çeşitli seskiterpenler oluşturmak için bir FPP molekülünü siklize eden vetipiradien siklaz enzimi için bir substrattır (Greenhagen ve ark., 2003). Böylece, SGA biyosentezi, seskiterpen ve triterpen öncülerinden oluşan birçok primer ve sekonder metabolit oluşumunun geniş bir kapsamı içerisinde meydana gelmektedir. SGA birikimi, çevresel streslere ve gelişimeye yanıt olarak biyosentetik döngünün farklı noktalarında düzenleniyor gibi görünmektedir (Choi ve ark., 1992). Patateslerde en önemli iki glikoalkaloid olan $\alpha$-solanin ve $\alpha$-çakonin (Şekil 1), solanidin olarak bir aglikondur, ancak farklı karbonhidrat yapılardan oluşmaktadırlar (Chowański ve ark., 2016; Wang ve ark., 2013). Genellikle $\alpha$-solanin ve $\alpha$-çakonin bitkilerde özellikle de patates bitkisinde birlikte sentezlenen glikoalkaloidlerdir ve $\alpha$ - çakonin $\alpha$-solanin'den daha toksiktir (Vaananen, 2007). $\alpha$-solanin'nin trisakkarit şeker parçaları D-glikoz, D-galaktoz ve L-ramnoz'a bağlı bulunan "solatrioz" olarak, $\alpha$-çakonin ise D-glikoz ve iki L-ramnoz molekülüne bağlı bulunan "çakotrioz" olarak adlandırılmaktadır (Vaananen, 2007). Diğer glikoalkaloidler ( $\beta$-solanin, $\gamma$-solanin, $\beta$ - çakonin, $\gamma$-çakonin, $\alpha$-solamarin, $\beta$-solamarin, 5 - $\beta$-solanidan-3-aol ve demissidin) patates bitkisinde çok düşük konsantrasyonlarda bulunmaktadır (Friedman ve ark., 1997).

\section{Patates Glikoalkaloidleri}

Aglikon ve glikozit yapısında olan ve kültürü yapılan patateslerde tanımlanan bazı SGA'lar Tablo 1'de verilmiştir. Kültür patateslerinde en sık tanımlanan SGA'lar solanidin, $\alpha$-çakonin ve $\alpha$-solanin'in trioz glikozitleridir. $\alpha$-çakonin ve $\alpha$-solanin patatesin içerdiği toplam SGA'ların \%95'ini oluşturmakta olup, toplam oranları doku, genotip ve gelişme koşullarına bağlı olarak geniş varyasyon göstermektedir (Friedman \& Dao, 1992; Sarquís ve ark., 2000).

Solanidan sınıfında leptininler ve leptinler olarak adlandırılan iki grup SGA'lar ile yakından ilgilidir. Yapraklardaki toplam SGA'ların oranı dikkate alındığında, leptin içeriği $\alpha$-solanin ve $\alpha$-çakonin içeriği ile ters orantılıdır (Ronning ve ark., 1998). Bu durum, $\alpha$-solanin ve $\alpha$-çakoninin ortak bir biyosentetik yol ve öncü substratları kullandığını göstermektedir. Bu leptinlerin miktarı patates böceği (Leptinotarsa decemlineata Say) zararına karşı bitki direnci ile ilişkili olduğu için oldukça önemlidir (Sinden ve ark., 1980, 1988). Bu nedenle, leptinler kültürü yapılan patateslerde genetik dayanıklıık sağlanması açısından geri melezleme kaynağı olarak düşünülmekte ve kimyasal pestisitlere alternatif kaynak oluşturmaktadırlar (Ronning ve ark., 1998).

\section{Patateste Glikoalkaloid Birikimi}

Patates yumrularının genetik olarak glikoalkaloid üretme kabiliyetleri oldukça farklıdır (Dale ve ark., 1993). Patates yumrularının glikoalkaloid içeriği patates çeşidine bağlıdır ve taze patates yumrularında 22,4-208,9 mg/kg arasında değişmektedir (Friedman \& McDonald, 1999). Finotti ve ark., (2006), farklı patates çeşitlerinin toplam glikoalkaloid içeriklerini inceledikleri çalışmalarında 


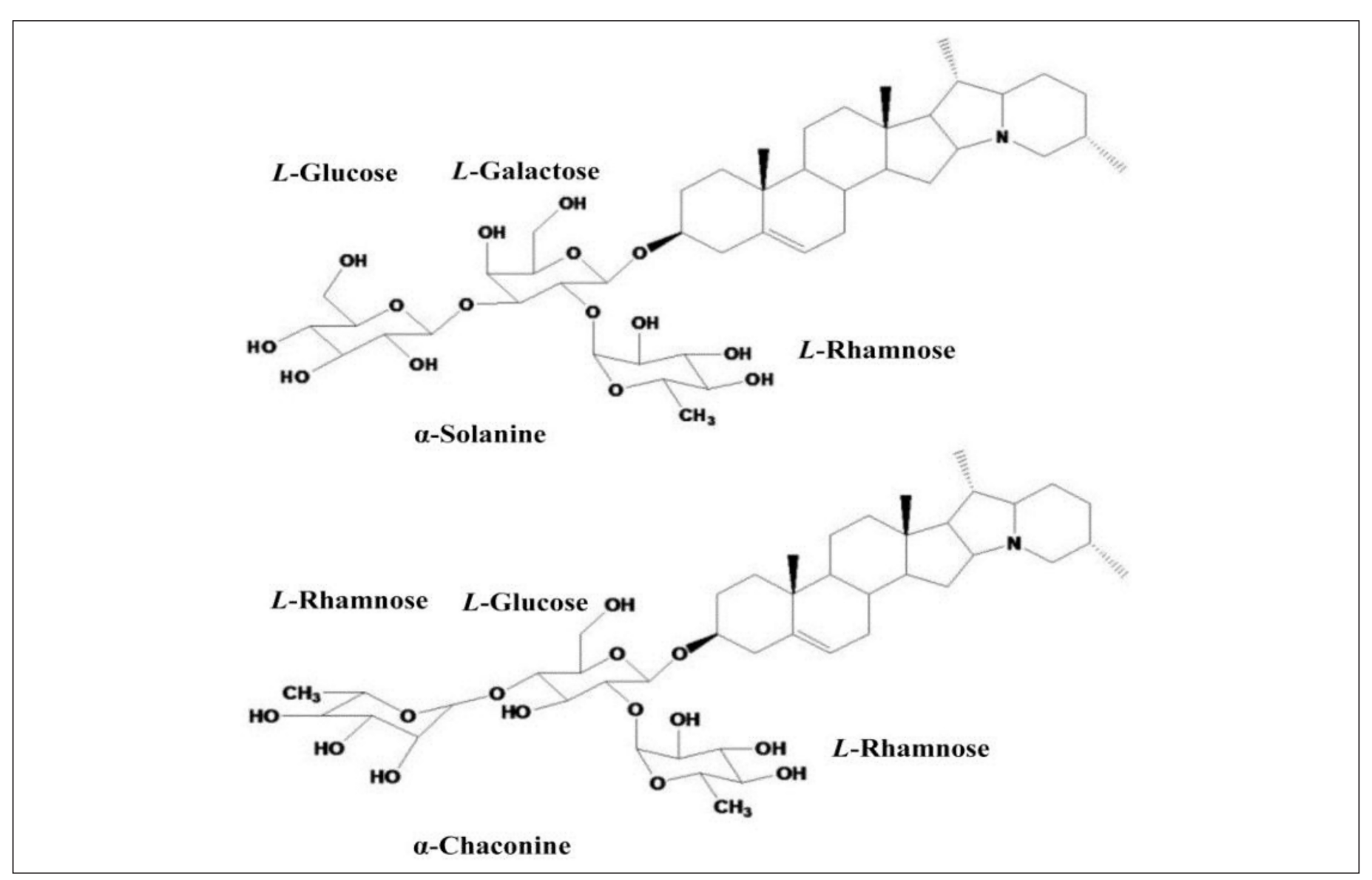

Şekil 1.

$\alpha$-Solanin ve $\alpha$-Çakonin Yapısı (Wang et al., 2013)

en düşük ve en yüksek toplam glikoalkaloid miktarlarını sırası ile Agata (1,04 mg/100 g) ve Sponta $(5,10 \mathrm{mg} / 100 \mathrm{~g})$ çeşitlerinde olduğunu bildirmişlerdir. Kırmızı etli (Rote Emma ve Rosemarie) patateslerdeki ortalama glikoalkaloid miktarları kabuklu yumrularda $24,41 \mathrm{mg} / 100 \mathrm{~g}$, soyulmuşta $6,02 \mathrm{mg} / 100 \mathrm{~g}$ ve kesilmişte $5,52 \mathrm{mg} / 100 \mathrm{~g}$ kuru madde, mavi etli yumrularda ise kabuklu yumruda 25,67 mg/100 g, soyulmuşta $7,73 \mathrm{mg} / 100 \mathrm{~g}$ ve kesilmişte 6,87 mg/100 g kuru madde olarak bulunmuştur (Rytel ve ark., 2013). Ingiltere'de geliştirilen patateslerin toplam glikoalkaloid içerikleri, bazı çeşitlerde daha yüksek seviyeler bildirilmiş olmasına rağmen, yaklaşık 25-150 mg/kg taze ağırlık olarak bildirilmiştir (Anonymous, 2016). Polonya'da yetiştirilen patates çeşitleri 12-159 mg/kg glikoalkaloid içerirken, Alman ve Amerikan çeşitlerinde bu değerlerin sırasıyla 20-220 mg/kg ve 20-130 mg / kg arasında olduğu bildirilmiştir. Lenape çeşidi Kanada ve ABD'de son derece yüksek glikoalkaloid içeriğine (30 mg/100 g) sahip olduğu için yasaklanmıştır (Dale \& Mackay, 2007; Nowacki, 2009). Benzer şekilde, Magnum Bonum çeşidi rapor edilen en yüksek seviye $66,5 \mathrm{mg} / 100 \mathrm{~g}$ taze ağırlık olmakla birlikte, ortalama 25,4 mg/100 g değeri ile yüksek toksik glikoalkaloid seviyesi nedeniyle İsveç'te yasaklanmıştır (Anonymous, 2016).

Yumrular elverişsiz iklim koşulları, hasat sırasında fiziksel yaralanma, yetersiz büyüme koşulları ve kötü depolama koşulları sonucu olarak da yüksek konsantrasyonlarda glikoalkaloid içerebilirler. Patates yumrularında ışı, sıcaklık, mekanik zarar, sürgün gelişimi ve fitopatojenler glikoalkaloid miktarının artmasına neden olmaktadır (Friedman, 2006; Kirui ve ark., 2009).
Glikoalkaloid oluşumu güneş ya da yapay ışığa maruz kalmanın bir sonucu olarak oluşabileceği gibi, hasattan sonra dikkatsiz taşıma ve depolama da yumrularda yüksek glikoalkaloid konsantrasyonlarına neden olmaktadır (Kasnak, 2015). Konu ile ilgili yapılan araştırmalarda depolama süresince SGA seviyesinin arttığı, artışın en fazla aydınlık koşullarda depolanan patateslerde olduğu ortaya konulmuştur (Şengül ve ark., 2004). Glikoalkaloid miktarının şiddetli ve hızlı artışına neden olması ve buna bağlı olarak tüketime yönelik olarak kullanılan yumrularda maksimum güvenlik sınırının üzerine çıkması nedeniyle öncelikle patates yumrularının hasat ya da depolama sırasında doğrudan güneş ışığına maruz kalmaları engellenmelidir (Kirui ve ark., 2009). Depolama devresinde ya da tarlada yumrular tam olarak toprakla örtülü olmadığı durumlarda herhangi bir ışık kaynağı glikoalkaloid miktarının artmasına neden olmaktadır (Dimenstein ve ark., 1997). Patates yumrularının hasat sırasında doğrudan güneş ışığına maruz kalmaları önlense de pazarlama aşamasında yumrular genellikle açık alan ya da raflarda ışığa maruz kalmaktadır. Bu durum, insanların glikoalkaloid seviyesi yükselen patates yumrularını satın alma riskini arttırmaktadır (Kirui ve ark., 2009).

Patates üretiminin yılın belirli dönemlerinde yapılıyor olması, yumruların belirli sürelerde depolanmalarını zorunlu kılmaktadır. Depolama işlemi patates yumrularında ağırlık ve kalite kayıplarının yanı sıra glikoalkaloid birikimine neden olabilmektedir. Marfona ve Granola patates çeşitlerinde toplam glikoalkaloid seviyelerinin depolama süresince sırasıyla 0,42-17,98 mg/kg ve 92-32,76 mg/kg arasında değiştiği ve SGA seviyesindeki en fazla 
artışın aydınlık koşullarda depolanan patateslerde olduğunu bildirilmiştir (Şengül, 2002). Farklı süre ve şekillerde depolanan Agria ve Bettina patates çeşitlerinde toplam glikoalkaloid miktarının depolama önce sırasyla 7,50 ve $8,53 \mathrm{mg} / \mathrm{kg}$ olduğu, bu değerlerin 56 günlük depo devresi sonunda dolaylı güneş ışığı koşullarında 120,32 ve 119,12 mg/kg, oda sıcaklığında karanlık koşullarda 49,19 ve $116,31 \mathrm{mg} / \mathrm{kg}$, karanlık buzdolabı koşullarında 52,03 ve 76,09 $\mathrm{mg} / \mathrm{kg}$, floresan + led ışık koşullarında ise 94,81 ve 234,31 mg/kg'a yükseldiği bildirilmiştir (Kasnak \& Artık, 2018). Depolama sürecinde özellikle market reyonlarında yüksek sıcaklık (oda sıcaklığı) ve aydınlatma ışığı gibi iki olumsuz faktör patates yumrularını etkilemektedir. Uzun süre bu faktörlerin etkisi altında kalan yumrularda sürgün gelişimi, yeşillenme ve gikoalkaloid birikimi gibi olumsuzluklar meydana gelmektedir. Yumrularda sürgün gelişiminin başlaması, patatesin solanin içeriğini 800-1000 mg/kg'a kadar yükseltebilmektedir (Cantwell, 1996). Tüketim amacıyla yumruların doğranması, parçalanması ve kesilmesi de glikoalkaloid miktarının artmasına neden olan faktörler arasında yer almaktadır (Mondy ve ark., 1987; Mondy \& Gosselin, 1988).

Tarımsal işlemelerin de glikoalkaloid içeriğini etkilediği bazı çalışmalarla ortaya konmuştur. Patates bitkisinde azotlu gübrelemenin toplam glikoalkaloid içeriğine etkilerinin araştırıldığı bir çalışmada farklı çeşitlerin glioalkaloid değişimi bakımından azot dozlarına tepkilerinin farklı olduğu, 40-120 kg/ha N uygulamalarında çeşitlerin ortalama glikoalkaloid içeriklerinin 1,74 mg/100 g'dan 1,94 mg/100 g'a çıktığı bildirilmiştir (TajnerCzopek ve ark., 2008). Diğer taraftan, organik olarak yetiştirilen patates yumrularının daha yüksek glikoalkaloid içerdikleri bildirilmiştir (Abreu ve ark., 2007; Hajslová ve ark., 2005; Wszelaki ve ark., 2005). Konu ile ilgili olarak, Skrabule ve ark., (2013), geleneksel yöntemle üretilen patates genotiplerindeki ortalama $\alpha$-solanin ve $\alpha$-chaconin miktarlarının sırası ile 0,94 mg/100 g ve 1,32 mg/100 $\mathrm{g}$; organik yöntemle üretilen genotiplerde ise bu değerlerin sırası ile 1,36 mg/100 g ve 1,50 mg/100 g olduğunu rapor etmişlerdir. Organik üretimde özellikle tarımsal ilaç kullanımının olmaması ve bu üretim şekli ile özel olarak ilişkilendirilen biyotik ve abiyotik stres faktörlerinin SGA'lar gibi doğal savunma metabolitlerinin biyosentezine neden olduğu düşünülmektedir (Friedman, 2006).

\section{Glikoalkaloidlerin Bitki Dokularındaki}

\section{Dağılımı}

Patateste SGA'lar, yumrunun öz kısmı hariç hemen hemen tüm dokularda bulunmaktadır. SGA'ların bitki dokularındaki oranı bitki gelişimi boyunca değiştiği gibi dokular arasında da değişmekte olup, çiçek ve sürgün dokularında daha yüksek miktarda bulunmaktadır (Eltayeb et al., 1997; Friedman \& McDonald, 1997; Valkonen et al., 1996). Yumrulardaki gözlerde, yaralı alanlarda ve sürgünlerde yüksek konsantrasyonlarda SGA bulunmasına rağmen, köklerindeki glikoalkaloid konsantrasyonu çok daha düşük seviyelerdedir. Nitekim SGA'ların bitkinin farklı dokuları arasında taşındıklarına dair bir araştırma sonucu da bulunmamaktadır (Sarquís et al., 2000). SGA'ların biyosentezi ve katabolizması doku veya organ düzeyinde düzenlenmektedir (Friedman \& McDonald, 1997). Yumrularda en yüksek SGA konsantrasyonu kabuğun hemen altındaki 1,5 mm'lik dokuda bulunmakta, bu miktar yumrunun iç kısmına doğru gidildikçe azalmaktadır (Valkonen et al., 1996).

Yapılan çalışmalarda, patateste toplam glikoalkaloid seviyelerinin, kuru kabuklarda 8,4-222,6 mg/100 g ve kuru ette 0,5-59,2 mg/100 g (Friedman at al., 2003), kuru kabukta 17,4-549,7 mg/100 g, kuru haşlanmış ette 64,2 mg/100 g (Sotelo et al., 2000) ve kuru kabukta 58,5-534,2 mg/100 g, kuru ette 0,7-46,6 mg/100 g (Deuber ve ark., 2012) arasında olduğu rapor edilmiştir. Farklı araştımacılar tarafından patates bitkisinin farklı kısımlarında bulunan glikoalkaloidlerin dağılımı Tablo 2'de verilmiştir. Bu tablodan da anlaşılacağı gibi patates bitkisinin farklı kısımları arasında glikoalkaloid miktarı önemli derecede farklılık göstermektedir.

\section{Glikoalkaloidlerin Bitki Savunma Sistemindeki Rolleri}

Bitki direncinin kaynağı olan SGA içeriğinin (özellikle $\alpha$-solanin ve $\alpha$-çakonin) kültürü yapılan patates çeşitlerinde tipik olarak düşük, yabani solanum cinsinin yaygın olarak kullanılan türlerinde ise yüksek konsantrasyonlarda bulunduğu bilinmektedir (Sarquís ve ark., 2000; Sinden ve ark., 1984). Yapılan bazı in-vitro çalışmalar, glikoalkaloidlerin patates patojenlerine ve zararlılarına karşı toksik etkisinin olduğunu göstermiştir (Allen \& Kuc 1968; Fewell \& Roddick, 1993, 1997; Roddick, 1987). Bu durum, SGA'ların bitkinin biyotik stres faktörlerine karşı savunma sistemlerine dahil olabileceği varsayımını kuvvetlendirmektedir (Gregory, 1984). Nitekim, glikoalkaloidlerin bitki yapraklarında yüksek seviyede bulunması ile geç yanıklık (Phytophthora infestans) enfeksiyonuna karşı yüksek dayanıklılık sağlandığı Andreu ve ark., (2001) tarafından da bildirilmiştir. SGA'lar, patateste viral ve mikrobiyal hastalıklara karşı direncin arttırılması gibi etkilere sahip olabildiği gibi (Austin ve ark., 1988; Fewell \& Roddick, 1997; Pehu ve ark., 1990; Percival ve ark., 1998; Rokka ve ark., 1994) böcek ve otçullar için de caydırıcı olmaktadır (Sanford ve ark., 1992, 1997).

Bazı SGA'ların tek başlarına düşük antifungal aktiviteye sahip olduğu, bununla birlikte farklı steroidal bileşiklerin kombinasyonlarının sinerjistik etkilerine bağlı olarak daha yüksek antifungal aktivite gösterdikleri saptanmıştır (Fewell \& Roddick, 1993; Roddick ve ark., 1988). Yapılan araştırmalarda $\alpha$-çakonin daha aktif olmak üzere $\alpha$-solanin ve $\alpha$-çakonin'nin birlikte daha yüksek antifungal aktiviteye sahip olduğu tespit edilmiştir (Cipollini \& Levey, 1997; Fewell \& Roddick, 1993). Friedman (2002), Clavibacter michiganense ile enfekte olmuş domates yapraklarında $\alpha$-tomatin birikiminin artarak bitkinin bakteriye karşı savunma sistemini güçlendirdiğini bildirmiştir (Sun et al., 2010). $\alpha$-solasonin ve $\alpha$-solamargin'nin Phoma medicaginis ve Rhizoctonia solani'ye karşı pH'ya bağlı sinerjik aktivite gösterdiği bildirilmiştir (Fewell et al., 1994).

Solanum SGA'ları, patates böceğine (Leptinotarsa decemlineata) karşı dirençte önemli rol oynamakta ve bu direnç genellikle patates yapraklarındaki glikoalkaloid seviyesinin yüksek olması ile ilişkilendirilmektedir (Lorenzen et al., 2001). Patates böceği zararı ile strese giren patateslerin yumruları direnç kazanmak için stressiz yumrulara göre daha yüksek seviyede SGA biriktirmektedir (Hlywka et al., 1994). Ayrıca yapraktaki yüksek solanin glikozitleri içeriği ile yaprak zararlılarına karşı direnç arasında doğrudan bir ilişki olduğu düşünülmektedir (Sanford et al., 1990). Glikoalkaloidlerin böcek öldürücü etkisine dayanarak yeni insektisitlerin kaynağı olmasına yönelik farklı çalışmalar yapılmaktadır (Chowański et al., 2016; Nenaah, 2011).

Patateste glikoalkaloidlerin temel görevleri, bitkiyi patojenler ve yaralanmalar gibi biyotik ve abiyotik stres faktörlerine karşı korumaktır (Navarre et al., 2009). Bu özellikleri nedeniyle SGA'lar doğal stres metabolitleri veya fitoaleksinler olarak tanımlanmaktadır. Alkaloidlerin biyolojikal aktiviteleri geniş spektrumlu olup; redoks dengesini bozma, biyolojikal zarları bozma, metabolizmayı bozma, 
kolinesteraz engelleme, artan ve sürekli toksisite oluşturma, gelişmeyi bozma, vb. fonksiyonları bulunmaktadır (Chowański et al., 2016). Solanum SGA'larının bitki savunma sisteminde önemli rol oynadığı birçok araştırma ile ispatlanmış olmasına rağmen, bazı organizmaların SGA'ları daha az toksik maddelere dönüştüren hidrolitik enzimlere sahip olduğu ve SGA'lara karşı dayanıklılık gösterebildiğini bildiren çalışmalar da mevcuttur (Osbourn, 1996; Tingey \& Sinden, 1982).

\section{Glikoalkaloid Toksisitesi}

Dünya Sağlık Örgütü tarafından, patates yumrularında güvenli glikoalkaloid seviyesi 1 kg taze ağırlıkta 20-100 mg olarak kabul edilmektedir (Anonymous, 1992). Ancak taze ağırlıkta 20 mg/100 g taze ağırlık seviyesinin üzerindeki glikoalkaloid seviyesi acı bir tada, gastroenterik semptomlara, komaya ve hatta ölüme bile yol açabilmektedir (Morris \& Lee, 1984). FAO / WHO Ortak Uzmanlar Komitesi (JECFA) patateste 100 mg/kg'dan az glikoalkaloid içeriğinin herhangi bir olumsuz etki göstermeyeceğini kabul etmektedir (Mensinga et al., 2005). Ancak, bazı araştırmacılar taze patateslerin $200 \mathrm{mg} / \mathrm{kg}$ glikoalkaloide kadar güvenli olduğunu belirtmektedir (Friedman et al., 1997; Jansky, 2010; Karim et al., 1997).

Glikoalkaloidlerin insanlara kıyasla, diğer hayvanlara karşı daha az toksik olduğu belirtilmektedir. Glikoalkaloidlerin en belirgin etkisi antikolinesteraz aktivitesi aracılığıyla merkezi sinir sistemi üzerine olmakta, hücre zarlarının bozulmasına neden olarak sindirim sistemi ve diğer organları olumsuz yönde etkilemektedir. Düşük seviyelerde glikoalkaloid alımı mide-bağırsak rahatsızlığına özellikle karın ağrısı, ishal ve kusmaya sebep olmaktadır (Hellenäs et al., 1992). Yüksek dozda alınan SGA'lar akut zehirlenmeye, nörolojik bozukluklara, hızlı nabız ve düşük tansiyona neden olurken, aşırı dozlarda koma veya ölüm gibi ciddi semptomlar yaşanabilmektedir (Friedman, 2006; Langkilde et al., 2009). Toksik doz, 1 kg vücut ağırlığında yaklaşık olarak 2-5 mg/kg-1 hesaplanırken, öldürücü dozun ise 1 kg vücut ağırlığı için 3-6 mg/kg-1 olduğu tahmin edilmektedir. Patates yumrularında acı tat oluşumu glikoalkaloid seviyesindeki artışın göstergelerinden birisi olup, glikoalkaloid içeriği 140 mg/kg'dan fazla olan patatesler de yaygındır (Johns \& Keen, 1986; Sinden et al., 1976; Zitnak \& Filadelfi, 1985). Yumrusunda 200 mg/kg'dan yüksek glikoalkaloid içeren çeşitler ise ağızda ya da boğazda yanmalara neden olmaktadır.

Birçok glikoalkaloid zehirlenmesi vakası vardır, ancak bu tür zehirlenme belirtileri bakteriyel gıda zehirlenmesine benzer olduğundan dolayı bunların hepsinin tanımlanması zor olmaktadır (Mensinga et al., 2005). Bu nedenle glikoalkaloid zehirlenmesi vakalarının önemli bir kısmı teşhis edilememiş ve yaklaşık 2000 vakada 30 insanın ölümüme yol açmıştır. Glikoalkaloidlerin toksikolojik çalışmaları çoğunlukla tavşanlar, fareler ve sıçanlar üzerinde gerçekleştirilmektedir. Fareler için $\alpha$-solanin, $\alpha$-çakonin ve tomatin için LD50 seviyeleri sırasıyla 27, 30 ve $34 \mathrm{mg} / \mathrm{kg}$ vücut ağırlığı olarak belirlenmiştir. Birçok hayvanda çeşitli glikoalkaloidler için öldürücü doz, vücut ağırlığının 30-60 mg/kg içinde olduğu belirtilmiştir. SGA'ların pişirme sırasında yok edilememesi nedeniyle (Maga, 1994; Smith et al., 1996), ticari çeşitlerin piyasaya sürülebilmesi için patates yumrularında $100 \mathrm{~g}$ taze ağırlık başına 20 mg SGA üst sınırı oluşturulmuştur (Valkonen et al., 1996).

\section{Glikoalkaloidlerin Olumlu Etkileri}

Patates glikoalkaloidlerinin insanlarda toksik etkilerinin yanı sıra faydalı etkileri de olabilmektedir (Friedman, 2002). Domateste bulunan $\alpha$-tomatin'in, plazma kolesterol ve trigliserit düzeylerini düşürmek için beslenmede hayati bir rol oynadığı bildirilmiştir (Friedman et al., 2000). $\alpha$ - çakonin'nin insan kanser hücresi olan HT-29'u parçaladığı (Lee et al., 2004; Yang et al., 2006) ve $\alpha$-solanin gibi diğer SGA'ların abanoz ve tahıllara karşı antialerjik olduğu kanıtlanmıştır (Golubeva, 1966). Ayrıca, $\alpha$-solanin'in hiperglisemik etkilere neden olabileceği (Usman, 2013) ve solamarjin'in anti-enflamatuar etkilere sahip olup herpes virüsüne ve kanser hücrelerine karşı hareket ettiği bildirilmiştir (Delporte et al., 1998). Bu nedenle, solanum SGA'larının kanser hücreleri ile mücadelede insanlar için oldukça faydalı olabileceği düşünülmektedir.

\section{Glikoalkaloidlerin Yıkımı}

Patatesin yumrularında ve sürgünlerinde ramnosidaz, galaktosidaz ve glukosidaz gibi hidrolitik enzimler içerdiği tespit edilmiştir (Swain et al., 1978). Bu enzimler, bitkilerin ototoksisiteden kaçınmasına yardımcı olabilmektdir. Ancak bu enzimlerin tamamen olgunlaşmış yumrulardaki aktiviteleri çok sınırlıdır. Patates kabuklarından izole edilmiş ve saflaştırılmış olan $\alpha$-çakonin ramnosidaz ve ramnoz'un hidrolizinde rol oynamaktadır (Bushway et al., 1988). Phytophthora infestans ile inkübe edildiğinde $\alpha$-solanin'in solanidin'e hidrolizi gözlenmiştir (Holland \& Taylor, 1979). SGA'ların biyolojikal aktiviteleri, aglikon'nun C3-OH durumuna bağlı olan karbonhidrat parçalarından üretilen şekerlerin sayı ve özelliklerinden etkilenmektedir (Rayburn et al., 1994). Bu nedenle, yumru dokularındaki hidrolize edici enzimlerin sentezlenmesi, SGA'ları indirgeyerek daha az toksik etki yapmasına öncülük etmektedir.

\section{Teknolojik Proseslerin Glikoalkaloid içeriğine Etkileri}

Patates üzerinde gerçekleşen teknolojik işlemlerin glikoalkaloidler üzerindeki etkisi Tablo 3'te verilmiştir. Patates yumrularındaki glikoalkaloid oranı soyma, doğrama ve su ile durulama gibi işlemler dahil olmak üzere çeşitli prosesler sırasında azaltılabilmektedir. Glikoalkaloidlerin genel içeriğine bağlı olarak bazı durumlarda soyulmuş patates yumrularında \%58'e kadar glikoalkaloid seviyesi azaltılabilmektedir (Tajner-Czopek et al., 2008, 2012). Patateslerin haşlanması, glikoalkaloid içeriğinin azaltılmasında soyma, doğrama ve durulama gibi işlemlere göre daha etkili olup, patates yumrularındaki glikoalkaloid miktarını ortalama

\section{Tablo 1.}

Kültürü Yapılan Patateslerde Tanımlanan Bazı Aglikon ve Glikozit Yapısında Olan SGA'lar (Sinden ve ark., 1980, 1988)

\begin{tabular}{|l|l|l|}
\hline Aglikon yapıdakiler & \multicolumn{2}{|c|}{ Glikozit yapıdakiler } \\
\hline & Trioz & Tetraoz \\
\hline Demissidin & Çakotrioz & Kommertetraoz \\
\hline Solanidin & Dihidrokakonin & Kommersonin \\
\hline Dihidroleptinidin & $\alpha$-Çakonin & Dehidrokommersonin \\
\hline Leptinidin & $\alpha$-Solanin & Dehidrodemissin \\
\hline Asetildihidroleptinidin & Leptinin & Demissin \\
\hline Asetilleptinidin & $\beta$-Soladulcin & Sisunin \\
\hline Soladulsidin & Leptin & Soladulsin B \\
\hline Solasodin & Soladulcine A & $\alpha$-Tomatin \\
\hline Tomatidin & Solamargin & Dehidrotomatin \\
\hline Tomatidenol & Solasonin & \\
\hline & $\beta$-Solamarin & \\
\hline & $\alpha$-Solamarin & \\
\hline & &
\end{tabular}




\begin{tabular}{|c|c|c|}
\hline $\begin{array}{l}\text { Patates } \\
\text { kısımları }\end{array}$ & $\begin{array}{c}\text { Toplam glikoalkaloid } \\
\text { miktarı (mg/kg taze ağırlık) }\end{array}$ & Kaynaklar \\
\hline Yaprak & $230-1450$ & $\begin{array}{l}\text { Friedman and Dao (1992); } \\
\text { Smith et al. (1996) }\end{array}$ \\
\hline Çiçek & $2150-5000$ & $\begin{array}{l}\text { Smith et al. (1996); Wood } \\
\text { and Young (1974) }\end{array}$ \\
\hline Meyve & $180-1350$ & $\begin{array}{l}\text { Friedman and Dao (1992); } \\
\text { Coxon (1981) }\end{array}$ \\
\hline Gövde & $23-33$ & $\begin{array}{l}\text { Smith et al. (1996); Wood } \\
\text { and Young (1974) }\end{array}$ \\
\hline Sürgün & 2000-9970 & $\begin{array}{l}\text { Friedman and Dao (1992); } \\
\text { Smith et al. (1996) }\end{array}$ \\
\hline Acı yumru & $250-800$ & $\begin{array}{l}\text { Smith et al. (1996); Wood } \\
\text { and Young (1974) }\end{array}$ \\
\hline $\begin{array}{l}\text { Normal } \\
\text { yumru }\end{array}$ & $10-150$ & Smith et al. (1996) \\
\hline - Kabuk & $150-1070$ & \\
\hline - Et & $12-100$ & \\
\hline - Korteks & 125 & \\
\hline - Öz & - & \\
\hline Kök & $180-850$ & $\begin{array}{l}\text { Friedman and Dao (1992); } \\
\text { Smith et al. (1996) }\end{array}$ \\
\hline
\end{tabular}

Tablo 3.

Patates Yumrusuna Uygulanan Işlemler Sonucu Glikoalkaloid Miktarındaki Azalma Oranları (Tajner-Czopek ve ark., 2008; Ji ve ark., 2012; Pęksa ve ark., 2006; Rytel ve ark., 2005)

\begin{tabular}{|l|l|}
\hline Işlem & $\begin{array}{l}\text { Toplam Glikoalkaloid } \\
\text { Azalması }\end{array}$ \\
\hline Kızartma & Ortalama \%94'e kadar \\
\hline Ağartma & Etkisi yok \\
\hline Kurutma & $\% 78-90$ \\
\hline Kaynatma & $\% 22$ \\
\hline Patates cipsi & Ortalama \%82'ye kadar \\
\hline Soyma & Ortalama \%58'e kadar \\
\hline Öğütme & Ortalama \%90'a kadar \\
\hline Kesme, dilimleme, su ile durulama & Etkisi yok \\
\hline Fırında ve tencerede pişirme & Etkisi yok \\
\hline
\end{tabular}

olarak \%22'ye kadar düşürebilmektedir. Glikoalkaloidlerin sudaki çözünürlüğünden dolayı bu süreçte glikoalkaloidlerin bir kısmı yumrulardan uzaklaşmakta, fakat uzaklaştırılan miktar genellikle önemsiz olmaktadır (Tajner-Czopek et al., 2008; Pęksa et al., 2006; Rytel et al., 2005). Patatesin endüstriyel olarak işlenmesi sırasında glikoalkaloid içeriğinin; soyulmamış yumrularda 16 $\mathrm{mg} / 100 \mathrm{~g}$, soyulduktan sonra $8,1 \mathrm{mg} / 100 \mathrm{~g}$, haşlama işleminden sonra 5,96 mg/100 g, soğutulduktan sonra $5,90 \mathrm{mg} / 100 \mathrm{~g}$, buharla muameleden sonra 3,81 mg/100 g, pnömatik kurutmadan sonra 3,39 mg/100 g, akışkan yataklı kurutucudan sonra $3,11 \mathrm{mg} / 100 \mathrm{~g}$, son olarak granüle üründe ise $2,66 \mathrm{mg} / 100 \mathrm{~g}$ kuru madde olarak tespit edilmiştir (Rytel, 2012).

Kızartma, fırınlama ve pişirme işlemlerinin karşılaştııılması sonucunda sadece kızartma işleminin yüksek çalışma sıcaklığından dolayı glikoalkaloid miktarını azalttığı tespit edilmiştir (Friedman \& Dao, 1992). Glikoalkaloidler çok yüksek ısıya dayanıkı olsalar da $\alpha$-solanin $260-270{ }^{\circ} \mathrm{C}$ arasındaki sıcaklıklarda ayrışmaktadır. Kızartma işleminin glikoalkaloid seviyesini düşürmede en etkili yöntem olduğu ve çiğ, soyulmuş ve kızartılmış patatesler arasındaki glikoalkaloid farkııı \%77-94 arasında değiştiği tespit edilmiştir (Tajner-Czopek et al., 2008; Pęksa et al., 2006; Rytel et al., 2005).

\section{Sonuç}

Genellikle patates yumrularındaki glikoalkaloid seviyesi genetik, çevresel ve fiziksel streslere bağlıdır. Hasat, nakliye veya depolama sırasında meydana gelen hasarlar da glikoalkaloid seviyesini yükseltmektedir. Yüksek sıcaklık dereceleri glikoalkaloid birikmesini uyarabileceği için, patateslerin uzun süre depolanması $7^{\circ} \mathrm{C}$ ve altındaki sıcaklıklarda yapılmalıdır. Patates yumrularında oda sıcaklığı ve ampul ışığı glikoalkaloid seviyesini yükseltir. Patates yumrularında en hızlı glikoalkaloid birikimi doğrudan güneş ışığına maruz kalma ile ortaya çıkmaktadır. Yumruların soyulması, dilimlenmiş yumruların suda kaynatılması veya kızartılması ve dehidrasyon ve granülasyon işlemleri ile glikoalkaloid seviyesinde önemli azalma sağlanabilmektedir. Kesme, dilimleme, suyla durulama, firınlama ve pişirme işlemleri patates yumrularında glikoalkaloid seviyesinin azaltılmasına herhangi bir etki göstermemektedir. Patates yumrularında oluşan acı tat, filizlenme ve yeşil kabuk oluşumu tüketicilerin glikoalkaloidlerle zehirlenmeyi önlemek için gözlemleyebilecekleri göstergelerdir. SGA'ların toksik etkilerinin yanı sıra antikanser ve antiviral aktivitelerle de ilişkilendirilmesi, düşük tüketimin bazı sağlık yararları sağlayabileceği anlamına gelmektedir. Sağlıkı veya fonksiyonel gıdalar kavramına yönelikyüksek toplum bilincinin oluştuğu bir çağda, SGA'lar, patatesin besin değerini iyileştirmek için değiştirilebilecek sekonder metabolitlerin bir örneği olarak görülmektedir

Bitkide toplam glikoalkaloid miktarı organlar arasında değişebildiği gibi aynı zamanda dokuların biriktirdiği glikoalkaloid çeşitleri de farklıık gösterebilmektedir. Bu durum, doku spesifisitesi kullanılarak glikoalkaloid dağıımının patates bitkisinin avantajına olacak şekilde düzenlenebileceği anlamına gelmektedir. Genetik manipülasyon yoluyla patates yapraklarında böceklere ve fungal enfeksiyonlara karşı yüksek dayanıklılık sağlayacak seviyede yüksek, yumrularda ise insan sağlığını tehdit etmeyecek seviyede düşük glikoalkaloid içeriğine sahip çeşitlerin geliştirilmesi ve SGA profillerinin dokuya özel uyarlanması gerekmektedir.

Hakem Değerlendirmesi: Dış bağımsız.

Yazar Katkıları: Fikir - F.Z.O., A.Ş.; Tasarım - F.Z.O., A.Ş.; Denetleme F.Z.O., A.S..; Kaynaklar - F.Z.O., A.Ş.; Literatür Taraması - F.Z.O., A.Ş.; Yazıyı Yazan - F.Z.O., A.Ş.; Eleştirel Inceleme - F.Z.O., A.Ş.

Çıkar Çatışması: Yazarlar çıkar çatışması bildirmemişlerdir.

Finansal Destek: Yazarlar bu çalışma için finansal destek almadıklarını beyan etmişlerdir.

Peer-review: Externally peer-reviewed.

Author Contributions: Concept - F.Z.O., A.Ş.; Design - F.Z.O., A.Ş.; Supervision - F.Z.O., A.Ş.; Resources - F.Z.O., A.Ş.; Literature Search - F.Z.O., A.Ş.; Writing Manuscript - F.Z.O., A.Ş.; Critical Review - F.Z.O., A.Ş.

Conflict of Interest: The authors have no conflicts of interest to declare.

Financial Disclosure:The authors declared that this study has received no financial support. 


\section{References}

Abreu, P., Relva, A., Matthew, S., Gomes, Z., \& Morais, Z. (2007). High-performance liquid chromatographic determination of glycoalkaloids in potatoes from conventional, integrated and organic crop systems. Food Control, 18(1), 40-44. [CrossRef]

Allen, E. H., \& Kuc, J. (1968). A-solanine and a- chaconine as Fungitoxic compounds in extracts of Irish Potato Tubers. Phytopathology, 58, 776-781.

Andreu, A., Oliva, C., Distel, S., \& Daleo, G. (2001). Production of phytoalexins, glycoalkaloids and phenolics in leaves and tubers of potato cultivars with different degrees of field resistance after infection with Phytophthora Infestans. Potato Research, 44(1), 1-9. [CrossRef]

Anonymous. (1992). Rome, Switzerland: Food and Agriculture Organization / World Health Organization, Joint Expert Committee on Food Additives.

Anonymous. (2016). PHP. Retrieved from http://www.safespectrum.com/ articles/potato toxicity-solanine, 1412. (Accessed date 25 December 2021).

Austin, S., Lojkowska, E., Ehlenfeldt, M. K., Kelman, A., \& Helgeson, J. P. (1988). Fertile interspecific somatic hybrids of Solanum: A novel source of resistance to Erwinia soft rot. Phytopathology, 78(9), 1216-1220. [CrossRef]

Bushway, A. A., Bushway, R. J., \& Kim, C. H. (1988). Isolaton, partial purification and characterization of a potato peel glycoalkaloid glycosidase. American Potato Journal, 65(11), 621-631. [CrossRef]

Cantwell, M. (1996). A review of important facts about potato glycoalkaloids. Perishables Handling Newsletter, 87, 26-27.

Choi, D., Ward, B. L., \& Bostock, R. M. (1992). Differential induction and suppression of Potato 3-hydroxy-3- methylglutaryl coenzyme a reductase genes in response to Phytophthora Infestans and to its elicitor arachidonic acid. Plant Cell, 4(10), 1333-1344. [CrossRef]

Chowański, S., Adamski, Z., Marciniak, P., Rosiński, G., Büyükgüzel, E., Büyükgüzel, K., ... Bufo, S. A. (2016). A review of bioinsecticidal activity of Solanaceae alkaloids. Toxins, 8(3), 1-28. [CrossRef]

Cipollini, M. L., \& Levey, D. J. (1997). Antifungal activity of Solanum fruit glycoalkaloids: Implications for frugivory and seed dispersal. Ecology, 78(3), 799-809. [CrossRef]

Coxon, D. T. (1981). The glycoalkaloid content of potato berries. Journal of the Science of Food and Agriculture, 32(4), 412-414. [CrossRef]

Dale, M. F. B., Griffiths, D. W., Bain, H., \& Todd, D. (1993). Glycoalkaloid increase in Solanum tuberosum on exposure to light. Annals of Applied Biology, 123(2), 411-418. [CrossRef]

Dale, M. F. B., \& Mackay, G. R. (2007). Inheritance of table and processing quality. Potato Genetics, 285-331.

Deahl, K. L., Cantelo, W. W., Sinden, S. L., \& Sanford, L. L. (1991). The effect of light intensity on Colorado potato beetle resistance and foliar glycoalkaloid concentration of four Solanum chacoense clones. American Potato Journal, 68(10), 659-666. [CrossRef]

Delporte, C., Backhouse, N., Negrete, R., Salinas, P., Rivas, P., Cassels, B. K., \& Feliciano, A. S. (1998). Antipyretic, hypothermic and antiinflammatory activities and metabolites from Solanum Ligustrinum lood. Phytotherapy Research, 12(2), 118-122. [CrossRef]

Deusser, H., Guignard, C., Hoffmann, L., \& Evers, D. (2012). Polyphenol and glycoalkaloid contents in potato cultivars grown in Luxembourg. Food Chemistry, 135(4), 2814-2824. [CrossRef]

Dimenstein, L., Lisker, N., Kedar, N., \& Levy, D. (1997). Changes in the content of steroidal glycoalkaloids in potato tubers grown in the field and in the greenhouse under different conditions of light, temperature and daylength. Physiological and Molecular Plant Pathology, 50(6), 391-402. [CrossRef]

Eltayeb, E. A., Al-Ansari, A. S., \& Roddick, J. G. (1997). Changes in the steroidal alkaloid solasodine during development of Solanum nigrum and Solanum İncanum. Phytochemistry, 46(3), 489-494. [CrossRef]

Elżbieta, R. (2012). The effect of industrial potato processing on the concentrations of glycoalkaloids and nitrates in potato granules. Food Control, 28(2), 380-384. [CrossRef]
Fewell, A. M., \& Roddick, J. G. (1993). Interactive antifungal activity of the glycoalkaloids A-solanine and A-chaconine. Phytochemistry, 33(2), 323-328. [CrossRef]

Fewell, A. M., \& Roddick, J. G. (1997). Potato glycoalkaloid impairment of fungal development. Mycological Research, 101(5), 597-603. [CrossRef]

Fewell, A. M., Roddick, J. G., \&Weissenberg, M. (1994). Interactions between the glycoalkaloids solasonine and Solamargin in relation to inhibition of fungal growth. Phytochemistry, 37(4), 1007-1011. [CrossRef]

Finotti, E., Bertone, A., \& Vivanti, V. (2006). Balance between nutrients and anti-nutrients in nine Italian potato cultivars. Food Chemistry, 99(4), 698-701. [CrossRef]

Friedman, M. (2002). Tomato glycoalkaloids: Role in the plant and in the diet. Journal of Agricultural and Food Chemistry, 50(21), 5751-5780. [CrossRef]

Friedman, M. (2004). Analysis of biologically active compounds in potatoes (Solanum tuberosum), tomatoes (Lycopersicon esculentum), and jimson weed (Datura stramonium) seeds. Journal of Chromatography. A, 1054(1-2), 143-155. [CrossRef]

Friedman, M. (2006). Potato glycoalkaloids and metabolites: Roles in the plant and in the diet. Journal of Agricultural and Food Chemistry, 54(23), 8655-8681. [CrossRef]

Friedman, M., \& Dao, L. (1992). Distribution of glycoalkaloids in potato plants and commercial potato products. Journal of Agricultural and Food Chemistry, 4O(3), 419-423. [CrossRef]

Friedman, M., Fitch, T. E., \& Yokoyama, W. E. (2000). Lowering of plasma LDL cholesterol in hamsters by the tomato glycoalkaloid tomatine. Food and Chemical Toxicology, 38(7), 549-553. [CrossRef]

Friedman, M., \& Mcdonald, G. M. (1999). Postharvest changes in glycoalkaloid content of potatoes. Advances in Experimental Medicine and Biology, 459, 121-143. [CrossRef]

Friedman, M., Mcdonald, G. M., \& Filadelfi-Keszi, M. F. (1997). Potato glycoalkaloids: Chemistry, analysis, safety and plant physiology. Critical Reviews in Plant Sciences, 16(1), 55-132. [CrossRef]

Friedman, M., Roitman, J. N., \& Kozukue, N. (2003). Glycoalkaloid and Calystegine contents of eight potato cultivars. Journal of Agricultural and Food Chemistry, 51(10), 2964-2973. [CrossRef]

Golubeva, S. N. (1966). Experiences in the diagnosis of food allergy and it's treatment with solanine. Vestnik Otorinolaringologii, 28(6), 23-27.

Greenhagen, B. T., Schoenbeck, M. A., Yeo, Y. S., \& Chappell, J. (2003). The chemical wizardry of isoprenoid metabolism in plants. In J. T. Romeo (Ed.), Integrative phytochemistry: From ethnobotany to molecular ecology (pp. 231-251). Amsterdam: Pergamon Press.

Gregory, P. (1984). Glycoalkaloid composition of potatoes: Diversity and biological implications. American Potato Journal, 61(3), 115-122. [CrossRef]

Hajslová, J., Schulzová, V., Slanina, P., Janné, K., Hellenäs, K. E., \& Andersson, Ch (2005). Quality of organically and conventionally grown potatoes: Four-year study of micronutrients, metals, secondary metabolites, enzymic browning and organoleptic properties. Food Additives and Contaminants, 22(6), 514-534. [CrossRef]

Hellenäs, K. E., Nyman, A., Slanina, P., Lööf, L., \& Gabrielsson, J. (1992). Determination of potato glycoalkaloids and their aglycone in blood serum by high-performance liquid chromatography: Application to pharmacokinetic studies in humans. Journal of Chromatography, 573(1), 69-78. [CrossRef]

Hlywka, J. J., Stephenson, G. R., Sears, M. K., \& Yada, R. Y. (1994). Effects of insect damage on glycoalkaloid content in potatoes (Solanum tuberosum). Journal of Agricultural and Food Chemistry, 42(11), 2545-2550. [CrossRef]

Holland, H. L., \& Taylor, G. J. (1979). Transformations of steroids and the steroidal alkaloid, solanine, by Phytophthora Infestans. Phytochemistry, 18(3), 437-440. [CrossRef]

Jansky, S. H. (2010). Potato flavor. American Journal of Potato Research, 87(2), 209-217. [CrossRef]

Ji, X., Rivers, L., Zielinski, Z., Xu, M., MacDougall, E., Stephen, J., Zhang, J. (2012). Quantitative analysis of phenolic components and 
glycoalkaloids from 20 potato clones and in vitro evaluation of antioxidant, cholesterol uptake, and neuroprotective activities. Food Chemistry, 133(4), 1177-1187. [CrossRef]

Johns, T., \& Keen, S. L. (1986). Taste evaluation of potato glycoalkaloids by the Ayamara: A case study in human chemical ecology. Human Ecology, 14(4), 437-452. [CrossRef]

Karim, M. S., Percival, G. C., \& Dixon, G. R. (1997). Comparative composition of aerial and subterranean potato tubers (Solanum tuberosum L). Journal of the Science of Food and Agriculture, 75(2), 251-257. [CrossRef]

Kasnak, C. (2015). Patateste Bazı Alkaloidlerin Depolama Sırasında Değişimi. (s. 176). (Doktora Tezi). Ankara Üniversitesi Fen Bilimleri Enstitüsü, Ankara.

Kasnak, C., \& Artık, N. (2018). Change in some nutritional value of potato under different storage conditions. Süleyman Demirel Üniversitesi Fen Bilimleri Enstitüsü Dergisi, 22(Özel), 330-338. [CrossRef]

Kirui, G. K., Misra, A. K., Olanya, O. M., Friedman, M., El-Bedewy, R., \& Ewell, P. T. (2009). Glycoalkaloid content of some superior potato (Solanum tuberosum L.) clones and commercial cultivars. Archives of Phytopathology and Plant Protection, 42(5), 453-463. [CrossRef]

Langkilde, S., Mandimika, T., Schrøder, M., Meyer, O., Slob, W., Peijnenburg, A., \& Poulsen, M. (2009). A 28-day repeat dose toxicity study of steroidal glycoalkaloids, A-solanine and A-chaconine in the Syrian golden hamster. Food and Chemical Toxicology, 47(6), 1099-1108. [CrossRef]

Lee, K. R., Kozukue, N., Han, J. S., Park, J. H., Chang, E. Y., Baek, E. J., Chang, J. S., \& Friedman, M. (2004). Glycoalkaloids and metabolites inhibit the growth of human colon (HT29) and liver (Hepg2) cancer cells. Journal of Agricultural and Food Chemistry, 52(10), 2832-2839. [CrossRef]

Lorenzen, J. H., Balbyshev, N. F., Lafta, A. M., Casper, H., Tian, X., \& Sagredo, B. (2001). Resistant potato selections contain leptine and inhibit development of the Colorado potato beetle (Coleoptera: Chrysomelidae). Journal of Economic Entomology, 94(5), 1260-1267. [CrossRef]

Maga, J. A. (1994). Glycoalkaloids in Solanaceae. Food Reviews International, 10(4), 385-418. [CrossRef]

Mensinga, T. T., Sips, A. J., Rompelberg, C. J., van Twillert, K., Meulenbelt, J., van den Top, H. J., \& van Egmond, H. P. (2005). Potato glycoalkaloids and adverse effects in humans: An ascending dose study. Regulatory Toxicology and Pharmacology, 41(1), 66-72. [CrossRef]

Mondy, N. I., \& Gosselin, B. (1988). Effect of peeling on total phenols, total glycoalkaloids, discoloration and flavor of cooked potatoes. Journal of Food Science, 53(3), 756-759. [CrossRef]

Mondy, N. I., Leja, M., \& Gosselin, B. (1987). Changes in total phenolic, total glycoalkaloid, and ascorbic acid content of potatoes as a result of bruising. Journal of Food Science, 52(3), 631-634. [CrossRef]

Morris, S. C., \& Lee, T. H. (1984). The toxicity and teratogenicity of Solanaceae glycoalkaloids, particularly those of the potato (Solanum tuberosum): A review. Food Technology in Australia, 36, 118-124.

Navarre, D. A., Goyer, A., \& Shakya, R. (2009). Nutritional value of potatoes: Vitamin, phytonutrient and mineral content. Advances in Potato Chemistry and Technology, 14, 395-424.

Nenaah, G. E. (2011). Toxic and Antifeedant activities of potato glycoalkaloids against Trogoderma granarium (Coleoptera: Dermestidae). Journal of Stored Products Research, 47(3), 185-190. [CrossRef]

NowackiW. (2009). Characteristics of native potato cultivars register. Plant Breeding and Acclimatization, 1-34.

Osbourn, A. E. (1996). Preformed antimicrobial compounds and plant defense against fungal attack. Plant Cell, 8(10), 1821-1831. [CrossRef]

Papathanasiou, F., Mitchell, S. H., Watson, S., \& Harvey, B. M. R. (1999). Effect of environmental stress during tuber development on accumulation of glycoalkaloids in potato (Solanum tuberosum L.). Journal of the Science of Food and Agriculture, 79(9), 1183-1189. [CrossRef]

Pehu, E., Gibson, R. W., Jones, M. G. K., \& Karp, A. (1990). Studies on the genetic basis of resistance to potato leaf roll virus, potato virus $Y$ and potato virus $X$ In Solanum brevidens using somatic hybrids of Solanum brevidens and Solanum tuberosum. Plant Science, 69(1), 95-101. [CrossRef]
Pęksa, A., Gołubowska, G., Aniołowski, K., Lisińska, G., \& Rytel, E. (2006). Changes of Glycoalkoaloids and nitrate contents in potatoes during chips processing. Food Chemistry, 97(1), 151-156. [CrossRef]

Percival, G. C., Karim, M. S., \& Dixon, G. R. (1998). Influence of light enhanced glycoalkaloids on resistance of potato tubers to Fusarium sulphureum and Fusarium solani Var. Coeruleum. Plant Pathology, 47(5), 665-670. [CrossRef]

Rayburn, J. R., Bantle, J. A., \& Friedman, M. (1994). Role of carbohydrate side-chains of potato glycoalkaloids in developmental toxicity. Journal of Agricultural and Food Chemistry, 42(7), 1511-1515. [CrossRef]

Roddick, J. G. (1987). Antifungal activity of plant steroids. In G. Fuller \& W D. Nes (Eds.), Ecology and metabolism of plant lipids. American Chemical Society Symposium 325. (pp. 286-303). Washington, DC: The American Chemical Society.

Roddick, J. G., Rijnenberg, A. L., \& Osman, S. F. (1988). Synergistic interaction between potato glycoalkaloid A-solanine an A-chaconine in relation to destabilization of cell membranes: Ecological implications. Journal of Chemical Ecology, 14(3), 889-902. [CrossRef]

Rokka, V. M., Xu, Y. S., Kankila, J., Kuusela, A., Pulli, S., \& Pehu, E. (1994). Identification of somatic hybrids of dihaploid Solanum tuberosum Lines and S. Brevidens by species specific RAPD patterns and assessment of disease resistance of the hybrids. Euphytica, 80(3), 207-217. [CrossRef]

Ronning, C. M., Sanford, L. L., Kobayashi, R. S., \& Kowalsld, S. P. (1998). Foliar leptine production in segregating $\mathrm{F} 1$, inter- $\mathrm{F} 1$, and backcross families of Solanum chacoense Bitter. American Journal of Potato Research, 75(3), 137-143. [CrossRef]

Rytel, E., Gołubowska, G., Lisińska, G., Pẹksa, A., \& Aniołowski, K. (2005). Changes in glycoalkaloid and nitrate contents in potatoes during French fries pro-cessing. Journal of the Science of Food and Agriculture, 85(5), 879-882. [CrossRef]

Rytel, E., Tajner-Czopek, A., Aniołowska, M., \& Hamouz, K. (2013). The influence of dehydrated potatoes processing on the glycoalkaloids content in coloured-fleshed potato. Food Chemistry, 141(3), 2495-2500. [CrossRef]

Sanford, L. L., Deahl, K. L., Sinden, S. L., \& Ladd, T. L. (1990). Foliar solanidine glycoside levels insolanum Tuberosum populations selected for potato leafhopper resistance. American Potato Journal, 67(7), 461-466. [CrossRef]

Sanford, L. L., Deahl, K. L., Sinden, S. L., \& Ladd, T. L. (1992). Glycoalkaloid contents in tubers from Solanum tuberosum populations selected for potato leafhopper resistance. American Potato Journal, 69(11), 693-703. [CrossRef]

Sanford, L. L., Kobayashi, R. S., Deahl, K. L., \& Sinden, S. L. (1997). Diploid and tetraploid Solanum chacoense genotypes that synthesize leptine glycoalkaloids and deter feeding by Colorado potato beetle. American Potato Journal, 74(1), 15-21. [CrossRef]

Sarquís, J. I., Coria, N. A., Aguilar, I., \& Rivera, A. (2000). Glycoalkaloid content in Solanum species and hybrids from a breeding program for resistance to late blight (Phytophthora Infestans). American Journal of Potato Research, 77(5), 295-302. [CrossRef]

Şengül, M. (2002). Depolanan Patateslerin Besin Öğelerinde ve Glikoalkaloid Seviyelerinde Meydana Gelen Değişimler. (s. 132). (Doktora Tezi). Atatürk Üniversitesi Fen Bilimleri Enstitüsü, Erzurum.

Şengül, M., Keleş, F., \& Keleş, M. S. (2004). The effect of storage conditions (temperature, light, time) and variety on the glycoalkaloid content of potato tubers and sprouts. Food Control, 15(4), 281-286. [CrossRef]

Sharma, R. P., \& Salunkhe, D. K. (1989). Solanum glycoalkaloids. In P. R. Cheeke (Ed.). Toxicants of plant origin (Vol. 1, pp. 179-236). USA: CRC Press Press.

Sinden, S. L., Deahl, K. L., \& Aulenbach, B. B. (1976). Effect of glycoalkaloids and phenolics on potato flavor. Journal of Food Science, 41(3), 520-523. [CrossRef]

Sinden, S. L., Sanford, L. L., Cantelo, W. W., \& Deahl, K. L. (1988). Bioassays of segregating plants. A strategy for studying chemical defences. Journal of Chemical Ecology, 14(10), 1941-1950. [CrossRef] 
Sinden, S. L., Sanford, L. L., \& Osman, S. F. (1980). Glycoalkaloids and resistance to the Colorado potato beetle in Solanum chacoense Bitter. American Potato Journal, 57(7), 331-343. [CrossRef]

Sinden, S. L., Sanford, L. L., \& Webb, R. E. (1984). Genetic and environmental control of potato glycoalkaloids. American Potato Journal, 61(3), 141-156. [CrossRef]

Skrabule, I., Muceniece, R., \& Kirhnere, I. (2013). Evaluation of vitaminS and glycoalkaloids in potato genotypes grown under organic and conventional farming systems. Potato Research, 56(4), 259-276. [CrossRef]

Smith, D. B., Roddick, J. G., \& Jones, J. L. (1996). Potato glycoalkaloids: Some unanswered questions. Trends in Food Science and Technology, 7(4), 126-131. [CrossRef]

Sotelo, A., \& Serrano, B. (2000). High-performance liquid chromatographic determination of the glycoalkaloids A-solanine and A-chaconine in 12 commercial varieties of Mexican potato. Journal of Agricultural and Food Chemistry, 48(6), 2472-2475. [CrossRef]

Sun, F., Li, S., He, D., Cao, G., Ni, X., Tai, G., Zhou, Y., \& Wang, D. (2010). Effects of glycoalkaloids from Solanum plants on cucumber root growth. Phytochemistry, 71(13), 1534-1538. [CrossRef]

Swain, A. P., Fitzpatrick, T. J., Talley, E. A., Herb, S. F., \& Osman, S. F. (1978). Enzymatic hydrolysis of A-chaconine and A-solanine. Phytochemistry, 17(4), 800-801. [CrossRef]

Tajner-Czopek, A., Jarych-Szyszka, M., \& Lisińska, G. (2008). Changes in glycoalkaloids content of potatoes destined for consumption. Food Chemistry, 106(2), 706-711. [CrossRef]

Tajner-Czopek, A., Rytel, E., Kita, A., Pęksa, A., \& Hamouz, K. (2012). The influence of thermal process of coloured potatoes on the content of glycoalkaloids in the potato products. Food Chemistry, 133(4), 1117-1122. [CrossRef]

Tingey, W. M., \& Sinden, S. L. (1982). Glandular pubescence, glycoalkaloid composition, and resistance to the green peach aphid, potato leafhopper, and potato fleabeetle in Solanum berthaultii. American Potato Journal, 59(3), 95-106. [CrossRef]

Usman, A. (2013). Effect of wounding and light exposure on sterol, glycoalkaloid, and Calystegine levels in potato plants (Solanum tuberosum L. Group Tuberosum) (Vol. 45, p. 21). Uppsala: Faculty of Natural Resources and Agricultural Sciences Department of Plant Biology and Forest Genetics.

Vaananen, T. (2007). Glycoalkaloid content and starch structure in Solanum species and interspecific somatic potato hybrids (pp. 1-79) [Ph.D. thesis]. Helsinki: University of Helsinki.

Valkonen, J. P. T., Keskitalo, M., Vasara, T., Pietilä, L., \& Raman, K. V. (1996). Potato glycoalkaloids: A burden or a blessing? Critical Reviews in Plant Sciences, 15(1), 1-20. [CrossRef]

Wang, H., Liu, M., Hu, X., Li, M., \& Xiong, X. (2013). Electrochemical determination of glycoalkaloids using A carbon nanotubes-phenylboronic acid modified glassy carbon electrode. Sensors, 13(12), 16234-16244. [CrossRef]

Wood, F. A., \& Young, D. A. (1974). TGA in potatoes. Canada Department of Agriculture, 1533, 1-3.

Wszelaki, A. L., Delwiche, J. F., Walker, S. D., Liggett, R. E., Scheerens, J. C., \& Kleinhenz, M. D. (2005). Sensory quality and mineral and glycoalkaloid concentrations in organically and conventionally grown redskin potatoes (Solanum tuberosum). Journal of the Science of Food and Agriculture, 85(5), 720-726. [CrossRef]

Yang, S. A., Paek, S. H., Kozukue, N., Lee, K. R., \& Kim, J. A. (2006). A- chaconine, A potato glycoalkaloid, induces apoptosis of HT-29 human colon cancer cells through caspase- 3 activation and inhibition of ERK $1 / 2$ phosphorylation. Food and Chemical Toxicology, 44(6), 839-846. [CrossRef]

Zitnak, A., \& Filadelfi, M. A. (1985). Estimation of taste thresholds of three potato glycoalkaloids. Canadian Institute of Food Science and Technology Journal, 18(4), 337-339. [CrossRef] 